\title{
Response of Lotus corniculatus to inoculation and pelleting on a range of Otago tussock grassland environments
}

HEATHER N. PATRICK AND W.L. LOWTHER Invermay Agricultural Centre, AgResearch, Private Bag, Mosgiel

\begin{abstract}
Results from oversowing experiments on a range of sites representative of undeveloped tussock grassland environments have shown that nodulation failures can limit establishment of Lotus corniculatus (birdsfoot trefoil). The problem appears to be primarily associated with poor survival and multiplication of rhizobia on/in the soil after sowing. Increasing the inoculation level above that stipulated by the manufacturer improved seedling nodulation. The magnitude of this improvement in nodulation varied over the sites used. Establishment from commercially pelleted seed was consistently low, with $<20 \%$ of seedlings nodulated on most sites. Inoculation of $L$. corniculatus with commercial peat inoculant at a rate of at least $30 \mathrm{~g}$ peat per $\mathrm{kg}$ seed, compared with the rates specified by manufacturers of $6.4 \cdot 19 \mathrm{~g}$, is recommended. Gum arabic at $10 \%$ (w:v) shouldbeincorporatedin the slurry and the seed should be sown within one day of inoculation. Further research is required to identify more adapted strains of rhizobia to improve nodulation of oversown $L$. corniculatus.
\end{abstract}

Keywords birdsfoot trefoil, establishment, Lotus corniculatus, nodulation, oversowing, rhizobia

\section{Introduction}

Rhizobia infective on Lotus corniculatus (birdsfoot trefoil) are absent from New Zealand soils, except for those few areas where L. tenuis or L. corniculatus have become naturalised (Greenwood \& Pankhurst 1977). and inoculation with effective rhizobia is essential for nodulation. However, little information is available on the inoculation and pelleting requirements of $\boldsymbol{L}$. corniculatus. Scott \& Charlton (1983) recommended commercially inoculated and coated seed or else inoculation immediately before use but results were not presented to support these recommendations. Chapman et of. (1990) indicated that nodulation failures. due to poor survival of rhizobiaon seed. could limit successful establishment of oversown $\boldsymbol{L}$. corniculatus. Nodulation was improved by inoculating seed at a high rate, with the incorporation of $10 \%$ gum arabic. and sowing within one day. Caution was expressed about commercially pelleted seed, which is more acceptable for use by farmers, because the interval between inoculation and sowing could result in low numbers of rhizobia and hence poor nodulation.

This paper presents results of two year's field experiments, and associated laboratory tests. designed to investigate more fully the standards required for inoculated and pelleted seed to establish $\boldsymbol{L}$. corniculatus successfully after oversowing onto tussock grassland environments.

\section{Materials and Methods}

The 1990 experiment compared four laboratory prepared inoculation and pelleting treatments with one commercially pelleted treatment. Seed of $\boldsymbol{L}$. corniculatus (cv Maitland) was inoculated with commercial peat inoculant (Nitrobug, Coated Seed Ltd., Christchurch) containing Rhizobium loti (strain SU343) as follows:

(a) Slurry-inoculated at the manufacturers specified rate of $19 \mathbf{g}$ peat per $\mathrm{kg}$ seed.

(b) Slurry-inoculated with $10 \%(\mathrm{w} / \mathrm{v})$ gum arabic added to the slurry.

(c) Inoculated and pelleted with $40 \%$ gum arabic as adhesive and microfine lime as coating material. (d) Inoculated at 5-times the manufacturers rate (95 $\mathbf{g}$ of peat per $\mathrm{kg}$ seed) and pelleted as in (c).

(e) Commercially pelleted (Prillcote ${ }^{\mathbf{R}}$, Coated Seed $\mathrm{Ltd}^{1}$., Christchurch).

Treatments a-d were prepared in the laboratory and after inoculation the seed was spread out and allowed to dry for 1 hour then placed in paper bags and stored at ambient temperature $\left(12-18^{\circ} \mathrm{C}\right)$ before sowing, 1 day after inoculation. Commercially pelleted seed was processed 7 weeks before sowing and stored at ambient temperature. The experiment consisted of five inoculation treatments randomised in four blocks at Berwen and Tara Hills. The design at Rocklands consisted of a five (inoculation) $\mathrm{x}$ two (lime) factorial randomised in four blocks.

1 Mention of a trademark. propriety product, or vendor \&es not constitute endorsement by AgResearch and does not imply its approval to the exclusion of other products or vendors that may also be suitable. 
The 1991 experiment compared four laboratory treatments and 10 commercially pelleted treatments applied to $L$. corniculatus (cv Dryland) seed. The following treatments were prepared as above:

(a) Slurry-inoculated with $10 \%$ gum arabic.

(b) Inoculated and lime pelleted.

(c) Inoculated at 5-times the manufacturers rate with $10 \%$ gum arabic.

(d) Inoculated at 5-times and lime pelleted.

(e-n) Commercially pelleted (Prillcote) processed 9,7,5,3 and 1 week before sowing, with each sample divided and stored at 4 and 15 " $\mathrm{C}$.

Treatments were randomised in four blocks at six sites (see Fig 1).

In both years, seed was sown by hand, in midSeptember, at a rate equivalent to $5 \mathrm{~kg} / \mathrm{ha}$ bare seed, on the sites representative of undeveloped Festuca novaezelandiae/Chionochloa rigida tussock grassland (Mark 1965) in Otago. Altitudes ranged from $600 \mathrm{~m}$ to $1100 \mathrm{~m}$.
A basal fertiliser dressing of molybdic superphosphate $(0.01 \% \mathrm{Mo} ; 9 \% \mathrm{P} ; 12 \% \mathrm{~S})$ at $\mathbf{2 0 0} \mathrm{kg} / \mathrm{ha}$ was applied at Rocklands while sulphur-molybdic-superphosphate $(0.01 \%$ Mo; 8\% P; $19 \%$ S) was applied to the othersites. At Rocklands. two lime treatments $(0$ or $1000 \mathrm{~kg} / \mathrm{ha})$ were applied in 1990, while in 1991 abasallimedressing of $1000 \mathrm{~kg} / \mathrm{ha}$ was applied.

Populations of rhizobia in the inoculants were counted by plate counts prior to use. The plant infection method (Brockwell 1963). with two replicate counts with 10fold dilutions, was used to estimate the populations of rhizobia on seed after 24 hours (1990), and population changes over the 4 days after inoculation (1991). Some counts exceeded the maximun detectible numbers.

When seedlings were at the cotyledon-unifoliate stage, 20 in each plot were pegged with wire markers and the number of nodulated seedlings was recorded 5-7 months after sowing. In addition, herbage mass of $\boldsymbol{L}$. corniculatus at Berwen and Rocklands was assessed 18 months after sowing by cutting to $2 \mathrm{~cm}$ height. Results from 1990 were analysed using a generalised linear
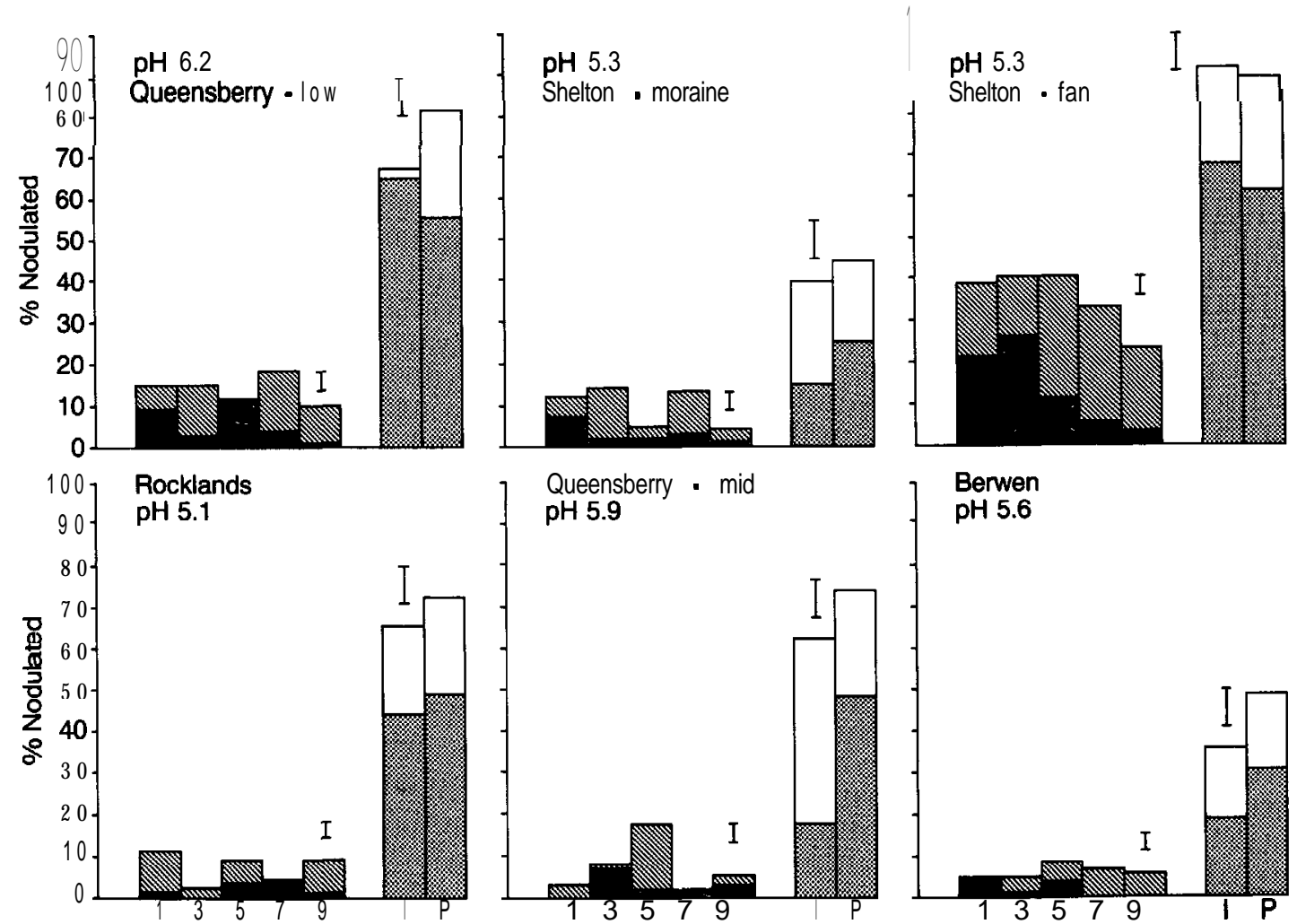

$(1,3,5,7,9=$ Age [weeks] of commercial pellet $)$

$\mathrm{I}=$ Slurry inoculation
$\mathbf{P}=$ Lime pellet

Storage temperature
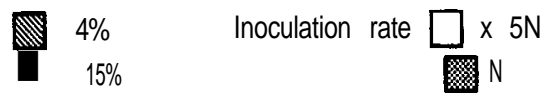

$15 \%$

Figure 1 Percentage of $\boldsymbol{L}$. corniculatus seedlings nodulated on. range of sites $\mathbf{5 . 7}$ months following oversowing with commercially pelleted, or laboratory inoculated and pelleted seed. Separate SED values are shown for commercial pellets and laboratory treatments. 
Table 1 Effect of inoculation and pelleting on the number of thizobia per seed at sowing and on percentage of nodulated $L$. corniculatus seedlings, with standard errors, 5 months after sowing.

\begin{tabular}{|c|c|c|c|c|c|c|}
\hline & \multirow{3}{*}{$\begin{array}{l}\text { Rhizobia } \\
\text { per seed } \\
\left(\begin{array}{l}x \\
\left.10^{3}\right)\end{array}\right.\end{array}$} & \multirow{3}{*}{$\begin{array}{l}\text { Sites: } \\
\text { Soil pH: } \\
\text { Lime: }\end{array}$} & \multirow{3}{*}{$\begin{array}{c}\text { Berwen } \\
5.6 \\
0\end{array}$} & \multicolumn{3}{|c|}{ Percent Nodulated Seedlings } \\
\hline & & & & \multirow{2}{*}{$\begin{array}{c}\text { Tara Hills } \\
5.2 \\
0\end{array}$} & \multicolumn{2}{|c|}{$\begin{array}{c}\text { RockJands } \\
5.1\end{array}$} \\
\hline & & & & & 0 & $1000^{3}$ \\
\hline $\begin{array}{l}\text { Inoculation (I)' } \\
\text { I g+u m arabic }\end{array}$ & $\begin{array}{l}6.7 \\
223\end{array}$ & & $\begin{array}{r}6 \pm 2.7 \\
14 \pm 4.0\end{array}$ & $\begin{array}{l}5 f 2.4 \\
8 \pm 3.0\end{array}$ & $\begin{array}{l}4 f 2.1 \\
\text { If } 1.2\end{array}$ & $\begin{array}{r}10 \pm 3.4 \\
30 \quad 5.2\end{array}$ \\
\hline I + lime pellet & $\overline{16.1}$ & & $19 f 4.4$ & $11 \pm 3.5$ & $11 \pm 3.6$ & $6+3.1$ \\
\hline x51 + lime pellet & 223 & & 53 i5. 6 & $15 \pm 4.0$ & $33 \pm 5.1$ & $42 f 5.4$ \\
\hline Commerclal pellet & 1.1 & & 0 & If 1.2 & $3 f 1.6$ & 0 \\
\hline
\end{tabular}

1 Seed slurry Inoculated at manufacturers specified rate

$210 \%$ gum arabic added to slurry

$3 \mathbf{~ k g} /$ ha broadcast lime

model for proportions of seedlings nodulated and an analysis of variance, after log transformation, for lotus herbage mass. In 1991. separate SEDs have been presented for nodulation from laboratory treatments and commercial pellets because of the large difference between the two sets of values.

\section{Results and discussion}

Laboratory inoculation and pelleting

Populations of rhizobia in the packets of commercial inoculant used in both years $(2.7$ - 6 x ldrhizobia per $\mathbf{g}$ peat) exceeded the requirements for certification by the Inoculant and Coated Seed Testing Service (Johnson 1979).

At the manufacturers specified rate $(19 \mathrm{~g}$ peat $/ \mathrm{kg}$ seed), seed was inoculated with $54.93 \times 10^{3}$ rhizobia. Chapman et al. (1990) reported lower numbers (21 x $\left.10^{3}\right)$, reflecting a different manufacturer's inoculation rate of $6.4 \mathrm{~g}$ peat $/ \mathrm{kg}$ seed. However, seed inoculated at the specified rate, with $10 \%$ gum arabic. had in excess of $23 \times 10^{3}$ rhizobia, 1 (1990:Table 1) and 4 (1991:Table 2a) days after inoculation compared with the $2.0 \times 10^{3}$ reported by Chapman et al. (1990). These higher numbers can be explained only partially by differences in initial inoculation levels and are mainly due to differences in survival of rhizobia on the seed after inoculation. This could be due to different survival characteristics between the strain of rhizobia used in the present experiments (SU343) and that used by Chapman et $\boldsymbol{a l}$. (PDDCC3663).

Increasing the inoculation level 5-fold, in the presence of lime pelleting, markedly increased nodulation on the Berwen and Rockland sites in 1990 (Table 1). On the acid (pH 5.1) Rocklands site, there was a virtual nodulation failure in the absence of broadcast lime or lime pelleting. Percentage nodulation was low in all
Table 2 Number of rhizobia per seed $\left(x 10^{3}\right)$ an: (a) laboratory inoculated and pelleted sced stored for up to 96 hours and: (b) commercially pelleted seed at sowing after up to 9 weeks storage at 4 and $15^{\circ} \mathrm{C}$.

(a)

\begin{tabular}{lccc}
\hline & \multicolumn{3}{c}{ Hours after inoculation } \\
\cline { 2 - 4 } & 4 & 25 & 96 \\
\hline $1+$ gum arabic' & 93 & 141 & 33 \\
$1+$ lime pellet & 141 & 43 & 12 \\
$\times 51+$ '3gum arabic & 1,431 & 761 & 243 \\
$\times 51+$ llme pellet & 761 & 351 & 167 \\
\hline
\end{tabular}

Seed slurry inoculated at manufacturers specified rate with $10 \%$ gum arabic added to slurry

(b)

\begin{tabular}{lccccc}
\hline Storage & \multicolumn{5}{c}{ Weeks } \\
\cline { 2 - 6 } temperature & 1 & 3 & 5 & 7 & 9 \\
\hline $4^{\circ} \mathrm{C}$ & $\geq 2.3$ & 22.3 & 22.3 & 1.3 & 1.6 \\
$15^{\circ} \mathrm{C}$ & 1.6 & 0.3 & 0.06 & 0.05 & 0.02 \\
\hline
\end{tabular}

treatments at Tara Hills, a result attributed to loss of seedlings due to moisture stress over summer. The response to increasing the inoculation level in 1991 varied over the sites (Fig 1), with the overall increase being significant $(41 \%$ vs $63 \%$; SED $=2.7 \%)$.

The present results show that nodulation problems in L. corniculatus cannot be solely attributed to very rapid death of rhizobia on the seed and the associated very low populations of rhizobia at sowing (Chapman et 01.1990). as low levels of nodulation occurred even with populations in excess of $23 \times 10^{3}$ rhizobia per seed. The critical phase in the nodulation process appears to be 
associated with the inability of the rhizobia to survive on the soil surface after sowing (e.g. Brockwell 1977) or multiply in the rhizosphere of the developing seedling root (e.g. van Egeraat 1975). The present results support the need for very high inoculation rates for oversown $L$. corniculatus ( Lowther \& Trainor 1988), to ensure good nodulation. particularly on the more difficult sites. However, further research is required to select a more adapted strain of rhizobia for use in $\boldsymbol{L}$. corniculatus inoculants to improve nodulation at practical levels of inoculation.

The importance of maximising the nodulation of seedlings was demonstrated by the significant treatment effects on L. comiculatus herbage mass (Table 3). The results also confii the effectiveness of the pegged plant technique in assessing different inoculation and pelleting treatments.

Table 3 Effect of incoulation treatments on $L$. corniculatus herbage mass (log $\mathrm{kg}$ DM/ha), 18 months after sowing, with backtransformed data in parenthesis.

\begin{tabular}{|c|c|c|c|c|c|}
\hline \multirow{3}{*}{$\begin{array}{l}\text { sites: } \\
\text { Llme (kg/ha): } \\
\text { Inoculation (l)' }\end{array}$} & \multirow{2}{*}{$\begin{array}{c}\text { Berwen } \\
0\end{array}$} & \multicolumn{4}{|c|}{ Rocklands } \\
\hline & & \multicolumn{2}{|l|}{0} & \multicolumn{2}{|c|}{1,000} \\
\hline & $3.83 \quad(45)$ & 1.57 & (4) & 3.28 & (28) \\
\hline$I+$ gum arabic ${ }^{2}$ & $3.38 \quad(28)$ & 3.00 & (19) & 5.13 & (188) \\
\hline I + lime pellet & $4.88 \quad(107)$ & 2.92 & (18) & 3.95 & (51) \\
\hline $\mathbf{x} 51+$ lime pellet & $5.88 \quad(288)$ & 3.11 & (21) & 5.77 & $(320)$ \\
\hline Commercial pellet & $1.83 \quad(5)$ & 0.01 & $(0)$ & 0.95 & (2) \\
\hline SED & 0.80 & \multicolumn{4}{|c|}{0.54} \\
\hline
\end{tabular}

1 Seed slurry Inoculated at manufacturers specifled rate

$210 \%$ gum arabic added to slurry

\section{Commercial pelleting}

The commercially pelleted $L$. corniculatus seed used in the 1990 trial had $1.1 \times 10^{3}$ rhizobia per seed at sowing at Tara Hills and Berwen but there was a virtual nodulation failure (Table 1). This result was surprising as although the pelleted seed had been processed 7 weeks before sowing, the number of rhizobia on the seed exceeded the $0.3 \times 10^{3}$ required for certification by the Inoculant and Coated Seed Testing Service (Johnson 1979).

More extensive testing of survival of rhizobia on commercially pelleted $\boldsymbol{L}$. corniculatus seed was carried out in 1991 (Table $2 \mathrm{~b}$ ). When stored at $4^{\circ} \mathrm{C}$, commercially pelleted seed had at least $2.3 \times 10^{3}$ rhizobia per seed 5 weeks after inoculation, and $1.6 \times 10^{3}$ after 9 weeks. In contrast. at $15^{\circ} \mathrm{C}$, there were only $0.08 \times 10^{3}$ and $0.02 \times 10^{3}$ rhizobia per seed after 5 and 9 weeks respectively. The low survival of $L$ corniculatus rbizobia at $15^{\circ} \mathrm{C}$ has important agricultural implications. Commercially pelleted seed is often stored at ambient temperature. both during transport and on the farm before use, and rapid death of rhizobia is likely. Therefore, commercial pellets may have low populations of rhizobia at sowing.

The percentage of seedlings nodulated, following oversowing with commercially pelleted seed, varied on the different tussock grassland sites. On five of the sites, less than $20 \%$ of seedlings from commercially pelleted seed nodulated, even with only 1 week's storage at $4^{\circ} \mathrm{C}$. In contrast. $35,81 \%$ of seedlings nodulated with seed inoculated in the laboratory at the high rate. On the Shelton-fan site, $38 \cdot 40 \%$ of seedlings nodulated with commercially pelleted seed stored for up to 6 weeks at $4^{\circ} \mathrm{C}$. This compares with $68 \%$ and $91 \%$ for inoculation at the normal and 5-times normal rate, respectively. On this site. nodulation was significantly higher when pelleted seed had been stored at $4^{\circ} \mathrm{C}$ than at $15^{\circ} \mathrm{C}$. It is clear that the standard of $0.3 \times 10^{3}$ rhizobia per seed developed for clover (Johnson 1979) is not relevant to $\boldsymbol{L}$. corniculatus oversown in tussock grassland environments, as commercially pelleted seed with at least $2.3 \times 10^{3}$ rhizobia at sowing gave low seedling nodulation on five out of six sites. There appears to be little chance of improving results from commercially pelleted seed unless a more suitable strain of rhizobia is selected.

\section{Conclusions}

Low rates of seedling nodulation caused by ineffective inoculation technology can limit establishment of $\boldsymbol{L}$. comiculatus oversown onto tussock grasslands. Nodulation failure can occur even when seeds have relatively high populations of rhizobia at sowing. The nodulation problem appears to be caused by the inability of the strain of rhizobia to survive on the soil surface or multiply in the soil. Increasing the rate of inoculation above the manufacturer's stipulated rate can increase nodulation.

To improve nodulation of $\boldsymbol{L}$. comiculatus at practical levels of inoculation. further research is required to select a strain of rhizobia with better survival/multiplication characteristics.

The variation in nodulation responses to inoculation and pelleting treatments on the different sites demonstrates the necessity for research into inoculation technology to be carried out on a range of environments to ensure widespread applicability of results. 


\section{ACKN OW LEDGEMENTS}

Peter Johnstone for trial design and statistical analysis, Kevin Trainor for fieldwork and Coated Seed Ltd., Christchurch for pelleted seed.

REFERENCES

Brockwell, J. 1963. Accuracy of a plant-infection technique for counting populations of Rhizobium trifolli. Applied microbiology 11: 377-383.

Brockwell. J. 1977. Application of legume seed inoculams. pp. 277-310. In Hardy, R.W.F. and Gibson, A.H. (Eds.), A Treatise on Dinitrogen Fixation. IV. Agronomy and Ecology. New York, John Wiley.

Chapman, H.M.; Lowther, W.L.; Trainor, K.D. 1990. Some factors limiting the success of Lotus corniculatus in hill and high country. Proceedings of the NZ Grassland Association 51: 147-150.

Egeraat, A.W.M. van 1975. The growth of Rhizobium leguminosarum on the root surface and in the rhizosphere of pea seedlings in relation to root exudates. Plant and soil 42: 367-379.

Greenwood, R.M.; Pankhurst, C.E. 1977. The Rhizobium component of the nitrogen-fixing symbiosis. Proceedings of the NZ Grassland Association 38: 167-174.

Johnson, D. 1979. Legumes. Seed inoculation. An introduction. Aglink FPP314. MAF, Wellington.

Lowther. W.L.; Trainor, K.D. 1988. Legumes. Seed inoculation and coating. Tussock grasslands procedure. Aglink FPP887. MAFCorp Primedia. Wellington.

Mark, A.F. 1965. Vegetation and mountain climate. In, Central Otago. New Zealand Geographical Society Miscellaneous Series 5. Lister, R.G. and Hargreaves, R.P. (Eds), pp. 69-91.

Scott, D.; Charlton. J.F.L. 1983. Birdsfoot trefoil (Lotus corniculatus) as a potential dryland herbage legume in New Zealand. Proceedings of the NZ Grassland Association 44: 98-105. 